\title{
Efeito do Uso do Solo nos Eventos de Cheia em Micro e Meso Escalas: Bacia do Potiribu
}

\author{
Omar B. da Silva Júnior, Carlos E. M. Tucci, Nilza M. R. Castro, Joel A. Goldenfum \\ Instituto de Pesquisas Hidráulicas IPH - UFRGS - Caixa Postal 15029 - CEP 91501-970 Porto Alegre, RS \\ omar@ppgiph.ufrgs.br,tucci@iph.ufrgs.br,nilza@iph.ufrgs.br,joe@iph.ufrgs.br
}

Recebido: 20/11/02 - revisado: 09/01/03 - aceito: 04/02/03

\begin{abstract}
Resumo
A alteração do uso e ocupação da superficie de uma bacia tem impactos significativos sobre o escoamento. A cobertura do solo influencia diretamente os processos hidrológicos como o escoamento superficial, capacidade de infiltração e interceptação da bacia. O efeito da mudança do tipo de plantio nos eventos de cheia na bacia do rio Potiribu, afuente do rio Ijui, foi analisado com base nos dados observados desde 1989 em bacias embutidas de diferentes escalas $\left(0,125 \mathrm{~km}^{2} ; 1,10 \mathrm{~km}^{2}\right.$ e 19,50 $\left.\mathrm{km}^{2}\right)$. Nestas bacias, o plantio convencional foi alterado para plantio direto em 1994. No estudo, foram analisados: as precipitacōes dos eventos de cheia, as vazões máximas, os volumes e os coeficientes de escoamento para os dois perídos. A sub-bacia de vertente $\left(0,125 \mathrm{~km}^{2}\right)$ tem pequena regularização e comportamento diferenciado das demais.

Observou-se, nos valores medidos, que, com o plantio direto, houve redução nos picos de cheia das bacias menores $\left(0,125 \mathrm{~km}^{2}\right.$ e $\left.1,10 \mathrm{~km}^{2}\right) e$ aumento na bacia maior $\left(19,50 \mathrm{~km}^{2}\right)$. No periodo de plantio direto, foi observada uma resposta bidrológica (escoamento superficial) mais uniforme do que no periodo de plantio convencional. Em eventos observados no plantio convencional, a menor bacia $\left(0,125 \mathrm{~km}^{2}\right)$ produr varões específicas maiores que as demais, como era de se esperar, porém, em eventos observados no plantio direto, é a bacia intermediária $\left(1,10 \mathrm{~km}^{2}\right)$ que gera as maiores vazões especificas.
\end{abstract}

Palavras-chave: plantio direto, escala hidrológica, variáveis hidrológicas

\section{INTRODUÇÃO}

A cobertura da superfície e o tipo do solo da bacia são de fundamental importância na geração dos escoamentos e sua divisão: superficial; sub-superficial e subterrâneo. A cobertura e tipo de solo influenciam diretamente a capacidade de infiltração, como, por exemplo, em florestas, a capacidade de infiltração e interceptação do solo é alta, o que produz pequena quantidade de escoamento superficial. Em solos com a superfície desprotegida, que sofrem a ação de compactação, a capacidade de infiltração pode diminuir consideravelmente (Tucci \& Clarke, 1997).

Em regiões agrícolas, as culturas anuais envolvem mudança da cobertura do solo ao longo do ano devido aos diferentes estágios de desenvolvimento da planta e aos diferentes tipos de plantio. Este processo envolve a preparação do solo (aragem) em determinadas épocas do ano, resultando na falta de proteção do solo em épocas que podem ser chuvosas. Normalmente, o preparo do solo é realizado antes do período chuvoso, porém, na região Sul do Brasil, não existe uma sazonalidade bem definida, podendo num determinado mês haver uma grande precipitação ou um período seco (Chevallier e Castro, 1991). Devido a esse regime pluviométrico, o solo pode estar sujeito à energia do impacto de chuvas intensas que tendem a pro- duzir erosão e modificar as condições de infiltração (Tucci e Clarke, 1997).

O plantio sem nenhum cuidado com a conservação do solo tende a aumentar consideravelmente a erosão, com grande aumento no escoamento com relação às condições prévias de floresta ou campo nativo. Adicionalmente, as estradas e as divisas de propriedades são geradoras de alterações do solo devido à erosão e à compactação que se forma (Tucci e Clarke, 1997).

Todas essas alterações na superfície do solo resultam em impactos na geração dos escoamentos da bacia. O conhecimento e a previsão desses impactos são de suma importância para a gestão de micro bacias rurais e o seu desenvolvimento.

Para compreender e explicar a influência da cobertura do solo nos escoamentos é preciso analisar os processos hidrológicos envolvidos. Devido à variabilidade dos processos hidrológicos é necessário verificar, então, os fenômenos dominantes em cada escala. Segundo Klemes (1983), uma variável hidrológica, como a vazão, em qualquer escala, origina-se de uma interação de um vasto número de fatores físicos de um nível menor. Em conseqüência, as leis num nível mais alto expressam médias ou integrais da lei dominante num nível mais baixo. Entretanto, Dooge (1997) afirma que diferentes leis podem ser estabelecidas em diferentes escalas e o conjunto apropriado 
de leis deve ser escolhido de acordo com a referida escala e com o tipo de problema a ser resolvido.

Em determinadas situações será possível estabelecer a ligação entre a formulação de relações hidrológicas em duas escalas adjacentes, estabelecendo conceitos e estimativas mais confiáveis das variáveis e parâmetros envolvidos. De outro lado, a ligação entre a formulação matemática e as variáveis e parâmetros em níveis adjacentes de análises pode ser tão complexa que nenhuma relação entre eles pode ser facilmente estabelecida.

A dinâmica das interações é influenciada pela escala em que cada fenômeno é estudado da mesma forma que as características da vegetação, pedologia e tipo de clima (Rodriguez-Iturbe, 2000).

Dentro desse contexto, nesse artigo, o efeito da mudança do tipo de plantio nos eventos de cheia na bacia do rio Potiribu, afluente do rio Ijuí, foi analisado com base nos dados observados desde 1989 em bacias embutidas de diferentes escalas $\left(0,125 \mathrm{~km}^{2} ; 1,10 \mathrm{~km}^{2}\right.$ e $\left.19,50 \mathrm{~km}^{2}\right)$. Nestas bacias, o plantio convencional foi alterado para plantio direto em 1994. No estudo, foram analisados: as precipitações dos eventos de cheia, as vazões máximas, os volumes e os coeficientes de escoamento para os dois períodos.

\section{BACIA DO RIO POTIRIBU}

A região estudada neste trabalho foi a bacia do rio Potiribu, localizada à noroeste do estado do Rio Grande do Sul numa posição central do derrame basáltico sulamericano (Figura 1). O rio é contribuinte da margem esquerda do Rio Ijuí, sendo este afluente da margem esquerda do Rio Uruguai.

Segundo Borges e Bordas (1990), a bacia do rio Potiribu pode ser considerada como representativa da região do planalto basáltico, uma região que se estende por $230.000 \mathrm{~km}^{2}$.

A bacia do rio Potiribu encontra-se sobre o planalto médio gaúcho com altitudes entre 420 e $700 \mathrm{~m}$. O relevo é composto de coxilhas com declividades suaves entre 3 e 15\%. Esse planalto é situado sobre a rocha basáltica, formada por acúmulo de sucessivas camadas vulcânicas datadas de 120 milhões de anos. Entre essas camadas, foram sendo depositadas camadas de arenito botucatu que variam de alguns metros de profundidade até uma centena de metros (Leinz, 1949, IBGE, 1986). Entre essas camadas, a água pode se acumular e escoar horizontalmente. Essa formação constitui a Serra Geral (Geologia do Brasil, 1984).

Sobre este planalto, os solos são bastante úmidos graças ao regime abundante de precipitações e constituem solos bem desenvolvidos e profundos, podendo atingir até mais de $15 \mathrm{~m}$. A maior parte do solo da região é classificada como latossolos roxos, latossolos vermelho-escuros e terras roxas estruturadas. Apesar de ser um solo argiloso (mais de 60\% de argila), ele apresenta uma forte drenagem devido aos microagregados formados em todo o perfil resultando em maior macro-porosidade (Castro, 1996).

O clima da região da bacia do rio Ijuí, segundo Beltrame (2000), está dentro da classificação mesotérmica brando superúmido sem seca (Cfa), assim descrita por Köppen: Cfa - temperatura média das máximas superior a $22{ }^{\circ} \mathrm{C}$ e a média das mínimas entre -3 e $18^{\circ} \mathrm{C}$ e verão quente. Segundo IPAGRO (1989), a temperatura média para a cidade de Cruz Alta (Figura 1) oscila entre 18 e 19 ${ }^{\circ} \mathrm{C}$, sendo julho o mês mais frio $\left(13-14{ }^{\circ} \mathrm{C}\right)$ e janeiro o mês mais quente $\left(24^{\circ} \mathrm{C}\right)$. A média das máximas é de $32^{\circ} \mathrm{C}$ e a média das mínimas fica em torno de $8{ }^{\circ} \mathrm{C}$.

A floresta primitiva é a Mata Atlântica e a Mata Araucária. Esta região é caracterizada por uma agricultura intensiva com dois ciclos de cultura por ano: soja e milho no verão e aveia e trigo no inverno.

As práticas agrícolas usualmente utilizadas na região noroeste do estado do Rio Grande do Sul são:

Conservacionista ou convencional - utiliza o terraceamento e plantio segundo as curvas de nível, para direcionar o escoamento e evitar a erosão e o dano às culturas.

Esse tipo de plantio tende a criar melhores condições para a infiltração nas chuvas de baixa ou média intensidade, mas, quando ocorre o rompimento do terraço nas cheias maiores, a água pode provocar ravinamento na direção da maior declividade do escoamento. Em alguns locais, tentou-se utilizar essa prática acompanhada pelo planejamento de microbacias, que retira as divisas das propriedades, organizando o uso do solo de acordo com microbacias e planeja as estradas vicinais.

Plantio direto - esse tipo de plantio não revolve a terra, é realizado diretamente sobre a superfície do solo, acima dos resíduos do plantio anterior, que são previamente secos. Antes do plantio, os resíduos da colheita anterior são picados e colocados na superfície do solo, onde são secos com a ajuda de produtos químicos. No momento do plantio, são abertos sulcos no solo onde os grãos são colocados. Nessa forma de plantio, a tendência é que, praticamente, toda a água se infiltre, e o escoamento ocorre, predominantemente, na camada sub-superficial. Esse tipo de plantio pode gerar problemas em áreas com grande declividade $(>15 \%)$, pois o escoamento sub-superficial, ao brotar na superfície, pode gerar erosão regressiva como a voçoroca. Em declividades mais suaves $(<5 \%)$ a erosão é reduzida já que o escoamento superficial é mínimo (Mendiondo et al., 1998).

O plantio direto produz maior regularização sobre o fluxo de estiagem e tende a apresentar também aumento do escoamento médio, se comparado com a floresta, devido à redução da evapotranspiração e interceptação. 


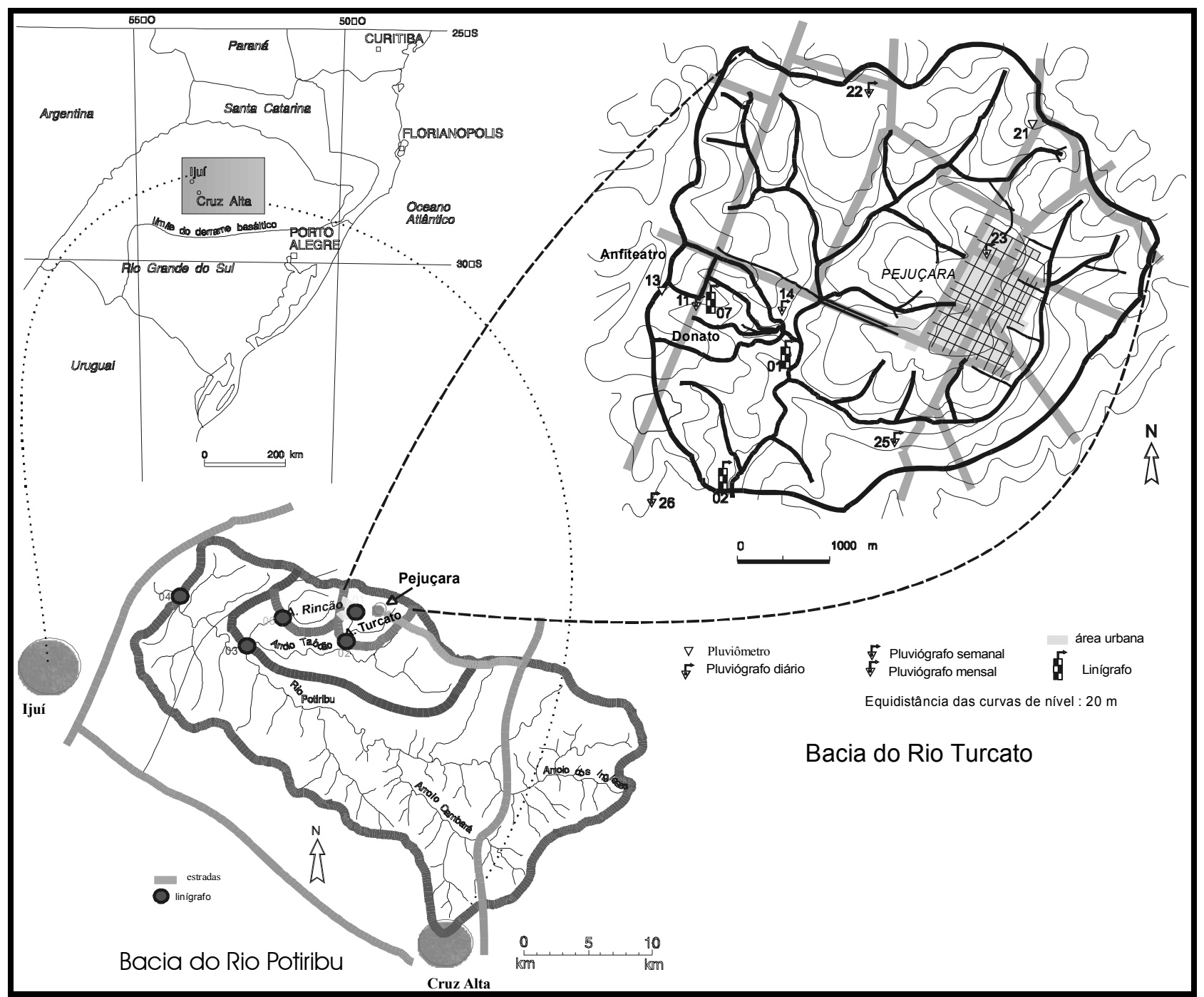

Figura 1 - Região em estudo: Bacia do rio Potiribu e Bacia do rio Turcato (Modificado de Castro et al., 2000)

A tendência é que a substituição da floresta por plantio com prática convencional também apresente aumento do escoamento médio, mas podendo reduzir o escoamento durante as estiagens, dependendo das características do solo e do aqüífero (Tucci e Clarke, 1997).

Nesta bacia, existe, desde 1989, monitoramento de três bacias embutidas: Anfiteatro, representativa de vertente $\left(0,125 \mathrm{~km}^{2}\right)$; Donato, micro bacia $\left(1,10 \mathrm{~km}^{2}\right)$; e Turcato uma bacia de escala de transição entre micro e meso escala $\left(19,5 \mathrm{~km}^{2}\right)$. As características morfológicas das três bacias são apresentadas na tabela 1 .

A bacia do Turcato (Figura 1), que engloba as bacias do Donato e do Anfiteatro, é uma bacia predominantemente agrícola, com um pouco de criação de gado e a cidade de Pejuçara ocupa a área de aproximadamente 10\% da bacia. Apresenta declividade média de 2,2\% (Tabela 1). $\mathrm{Na}$ bacia, existe pouca vegetação, alguns bosques e mata de galeria. Segundo Silva Júnior (2001), a bacia do Turcato tem comportamento hidrológico similar ao de bacias de meso escala $\left(100-10.000 \mathrm{~km}^{2}\right)$.

Tabela 1 - Características físico-morfológicas das bacias estudadas (Chevallier, 1993)

\begin{tabular}{llll}
\hline Bacia & Anfiteatro & Donato & Turcato \\
\hline Altitude máxima $(\mathrm{m})$ & 468,7 & 468,7 & 485 \\
Área $\left(\mathrm{km}^{2}\right)$ & 0,125 & 1,10 & 19,5 \\
$\begin{array}{l}\text { Perímetro }(\mathrm{km}) \\
\text { Índice de compacidade }\end{array}$ & 1,42 & 4,54 & 17,9 \\
$\begin{array}{l}\text { Comprimento do retân- } \\
\text { gulo equivalente (km) }\end{array}$ & 0,41 & 1,22 & 1,14 \\
$\begin{array}{l}\text { Desnível }(\mathrm{m}) \\
\text { Índice de declividade } \\
\text { global }(\mathrm{m} / \mathrm{km})\end{array}$ & 38,0 & 1,60 & 5,42 \\
\hline
\end{tabular}


A bacia do Donato possui dois canais principais (Figura 1), com declividade média de 5,1\%. É totalmente agrícola e apresenta somente mata de galeria. É atravessada por uma estrada não asfaltada e pertence a apenas três proprietários rurais.

A bacia do Anfiteatro, a menor das bacias monitoradas pelo Projeto Potiribu, possui um canal não permanente e um talvegue muito curto. Esta parcela fica dentro da bacia do Donato (Figura 1). Esta bacia pertence a um único proprietário, sendo totalmente agrícola. A pouca vegetação que possuía próxima a estrada foi destruída no início dos anos 90 .

O uso do solo nas bacias foi marcante no período de monitoramento. Entre 1989 e 1994, a área das bacias estudadas tinha como prática o plantio convencional com terraço e plantio em curvas de níveis. Desde o final da década de 80 , a região começava a adotar o plantio direto, mas foi no período de plantio de 1994 que houve uma completa alteração para o plantio direto, que ocorre até hoje (Castro, 1996). Portanto, os períodos de uso do solo da bacia adotados, neste trabalho, foram:

- convencional - de 1989 até 1994; e

- $\quad$ direto - de 1994 a 1999.

\section{DISPONIBILIDADE DE DADOS}

A seguir, são descritos os aparelhos pluviométricos e fluviométricos mantidos pelo projeto Potiribu (Castro et al., 2000).

\section{Postos Pluviométricos e Pluviográficos}

Os aparelhos instalados no Potiribu descritos por Castro et al. (2000) foram instalados em novembro de 1989, de maneira a cobrir a bacia do rio Taboão $\left(100 \mathrm{~km}^{2}\right)$, na qual a bacia do Turcato é embutida. Estes aparelhos são de dois tipos: pluviógrafos (Tabela 2) e pluviômetros (Tabela 3). Eles podem ser localizados na Figura 02.

Em abril de 1998, o projeto contava com apenas 7 postos de pluviometria (aparelhos 13, 32, 34, 35, 36, 52 e 61) e 3 de pluviografia (aparelhos 14, 23 e 51). Os postos que têm registros mais confiáveis, segundo Castro et al. (2000), são os aparelhos de pluviometria 13 e 52 e os de pluviografia 14 e 51 .

\section{Postos Fluviométricos}

A Tabela 4 apresenta características gerais dos linígrafos instalados em cada posto fluviométrico. Observase na 4 a coluna desta tabela que, em alguns casos, os postos apresentam mais de $20 \%$ de lacunas, devido a problemas com os aparelhos e dificuldade de obter pessoal e verba para operá-los.

Os postos que continuam funcionando até o momento são: o Anfiteatro; o Donato e o Turcato, sendo que o último foi interrompido entre 12/1995 e 07/1998. Estes postos são descritos mais detalhadamente a seguir.

Posto Fluviométrico Anfiteatro: Os escoamentos superficiais na bacia do Anfiteatro são coletados pela valeta na margem noroeste da estrada de terra que atravessa a bacia do Donato e dá acesso a algumas casas isoladas e às lavouras. No ponto mais baixo dessa valeta, um bueiro permite o escoamento sob a estrada. Uma obra de concreto a montante do bueiro coleta as vazões vindo diretamente da bacia e das valetas.

A jusante da estrada, há outra obra, constituída de um pequeno canal retangular de fundo triangular com dois metros de comprimento, que possibilita medir as descargas com molinete. Neste canal, localiza-se a tomada d'água para o linígrafo.

A curva-chave foi obtida a partir de 24 medições de vazão na saída do bueiro do Anfiteatro com alturas d'água entre 3 e $7 \mathrm{~cm}$. A cota máxima registrada foi de 28 $\mathrm{cm}$ no dia 24 de outubro de 1992 às $13 \mathrm{~h} 33 \mathrm{~min}$. A curva chave foi extrapolada através da fórmula de Manning até a cota de $30 \mathrm{~cm}$.

Posto Fluviométrico Donato: O posto hidrométrico foi instalado em novembro de 1989 num trecho reto a jusante da confluência dos três cursos permanentes de água que constituem a rede hidrográfica da bacia, a aproximadamente $200 \mathrm{~m}$ a montante da confluência com o arroio Turcato.

A seção de medição foi estabilizada em março de 1991 com a construção de uma soleira de concreto e a retificação do leito. Foram realizadas 26 medições de vazão na estação Donato depois da construção da soleira entre 28 e $120 \mathrm{~cm}$. Exceto no período de 26 de maio de 1992 a 10 de julho de 1992, o escoamento sempre ficou entre as paredes da soleira $(\mathrm{h}<280 \mathrm{~cm})$ e atingiu o nível máximo de $241 \mathrm{~cm}$ no dia 05 de dezembro de 1993 às $6 \mathrm{~h}$. A curva-chave foi obtida calibrando as medições a uma fórmula teórica.

Nos dias 26 e 27 de maio de 1992 ocorreram chuvas excepcionais que causaram uma cheia cujo nível d'água passou sobre a obra, atingindo a cota $321 \mathrm{~cm}$ no dia 27 , às $12 \mathrm{~h} 06$, e derrubou uma parte da margem direita da estação e a água abriu uma passagem pelo lado externo do pilar direito da soleira. Essa abertura só foi fechada no início de julho de 1992.

Conseqüentemente, uma nova curva-chave foi estabelecida, válida de maio de 1992 às $11 \mathrm{~h} 20$ min até o dia 09 de julho de 1992 às 23h59min. Depois de 09 de julho a primeira curva-chave voltou a ser válida.

Posto Fluviométrico Turcato: $\mathrm{O}$ posto hidrométrico foi instalado em novembro de 1989 num trecho reto e bem encaixado a jusante de uma pequena zona de inundação. 


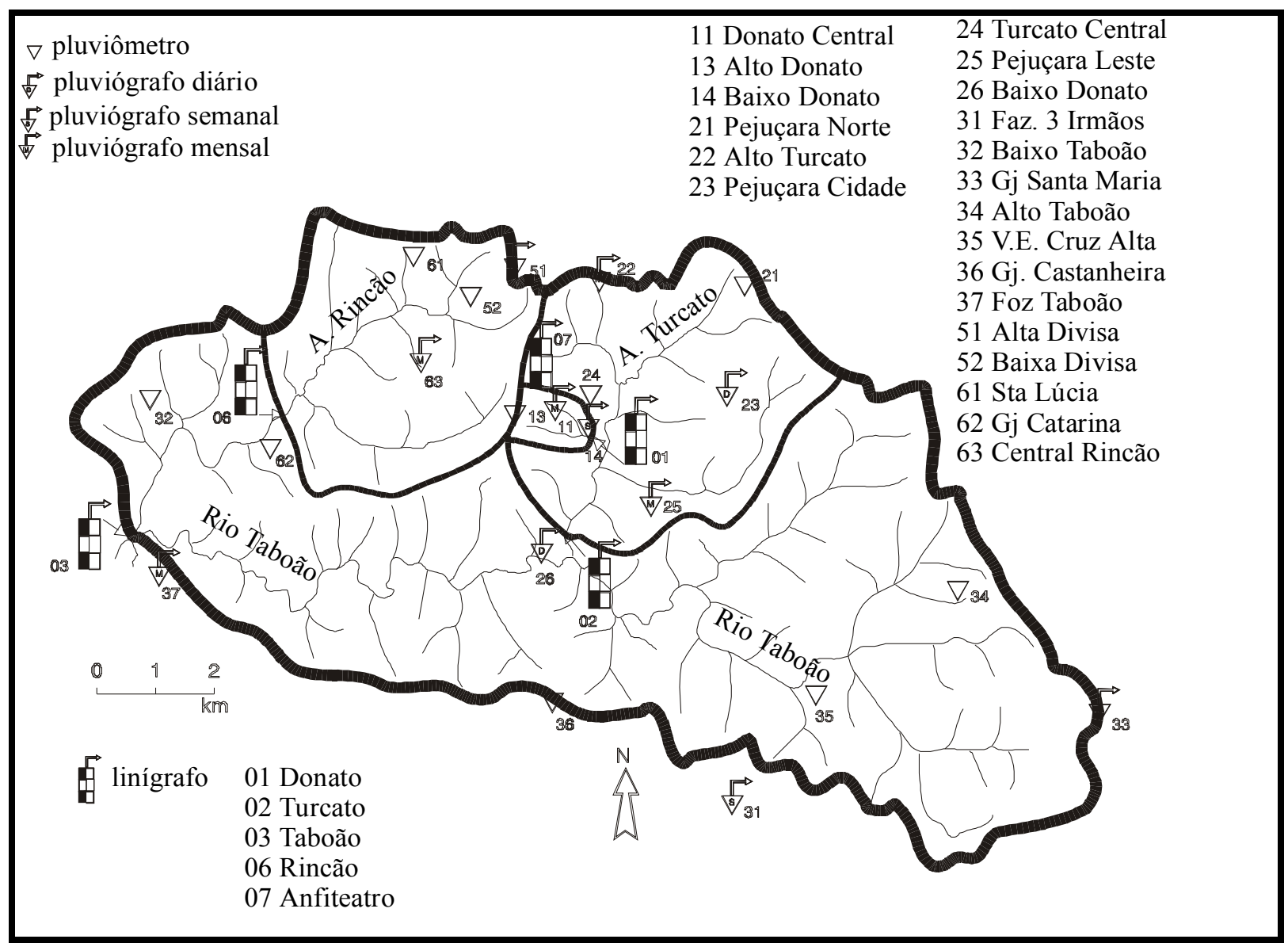

Figura 2 - Localização dos postos pluviométricos (Modificado de Castro et al., 2000)

Tabela 2 - Relação dos pluviógrafos (Castro et al., 2000)

\begin{tabular}{|c|c|c|c|c|c|c|c|}
\hline Código & Nome & $\begin{array}{l}\text { Longitude } \\
\text { Oeste }\end{array}$ & $\begin{array}{l}\text { Latitude } \\
\text { Sul }\end{array}$ & Aparelho & $\begin{array}{l}\text { Data } \\
\text { Início }\end{array}$ & fim & $\begin{array}{l}\% \text { func. } \\
\text { até } 12 / 98\end{array}$ \\
\hline 11 & Donato Central & $53^{\circ} 41^{\prime} 13^{\prime \prime}$ & $28^{\circ} 25^{\prime} 15^{\prime \prime}$ & $\begin{array}{l}\text { Lambrecht } \\
\text { IH Hidromec3 }\end{array}$ & $\begin{array}{l}29 / 11 / 89 \\
25 / 04 / 91\end{array}$ & $\begin{array}{l}25 / 04 / 91 \\
17 / 01 / 96\end{array}$ & $80,8 \%$ \\
\hline 12 & Baixo Donato & $53^{\circ} 40^{\prime} 35^{\prime \prime}$ & $28^{\circ} 25^{\prime} 35^{\prime \prime}$ & IH PLG 7S & $07 / 11 / 89$ & $14 / 12 / 90$ & $94,4 \%$ \\
\hline 14 & Baixo Donato & $\begin{array}{l}53^{\circ} 40^{\prime} 12^{\prime \prime} \\
53^{\circ} 40^{\prime} 31^{\prime \prime}\end{array}$ & $\begin{array}{l}28^{\circ} 25^{\prime} 18^{\prime \prime} \\
28^{\circ} 25^{\prime} 09^{\prime \prime}\end{array}$ & $\begin{array}{l}\text { IH PLG 7S } \\
\text { IH PLG 7S }\end{array}$ & $\begin{array}{l}14 / 12 / 90 \\
23 / 07 / 98^{* *}\end{array}$ & & $85,6 \%$ \\
\hline 22 & Alto Turcato & $53^{\circ} 39^{\prime} 53^{\prime \prime}$ & $28^{\circ} 24^{\prime} 02^{\prime \prime}$ & Lambrecht & $10 / 11 / 89$ & $30 / 09 / 95$ & $53,6 \%$ \\
\hline 23 & Pejuçara Cidade & $\begin{array}{l}53^{\circ} 39^{\prime} 14^{\prime \prime} \\
53^{\circ} 39^{\prime} 34^{\prime \prime}\end{array}$ & $\begin{array}{l}28^{\circ} 25^{\prime} 05^{\prime \prime} \\
28^{\circ} 25^{\prime} 10^{\prime \prime}\end{array}$ & $\begin{array}{l}\text { IH PLG 7S } \\
\text { IH PLG } 4\end{array}$ & $\begin{array}{l}21 / 08 / 89 \\
06 / 11 / 89 * \\
09 / 05 / 98^{* *}\end{array}$ & $06 / 11 / 89$ & $80,9 \%$ \\
\hline 25 & Pejuçara Leste & $53^{\circ} 39^{\prime} 41^{\prime \prime}$ & $28^{\circ} 26^{\prime} 00^{\prime \prime}$ & $\begin{array}{l}\text { Lambrecht } \\
\text { IH Hidromec3 }\end{array}$ & $\begin{array}{l}22 / 05 / 90 \\
05 / 11 / 92\end{array}$ & $\begin{array}{l}05 / 11 / 92 \\
10 / 02 / 96\end{array}$ & $44,8 \%$ \\
\hline 26 & Baixo Turcato & $53^{\circ} 41^{\prime} 39^{\prime \prime}$ & $28^{\circ} 26^{\prime} 29^{\prime \prime}$ & IH PLG 4 & $08 / 11 / 89$ & $31 / 12 / 95$ & $76,8 \%$ \\
\hline 31 & $\begin{array}{l}\text { Fazenda Três } \\
\text { Irmãos }\end{array}$ & $53^{\circ} 40^{\prime} 18^{\prime \prime}$ & $28^{\circ} 28^{\prime} 24^{\prime \prime}$ & IH PLG 7S & $28 / 08 / 89$ & $12 / 05 / 94$ & $85,6 \%$ \\
\hline 33 & $\begin{array}{l}\text { Granja Santa } \\
\text { Maria }\end{array}$ & $53^{\circ} 35^{\prime} 00^{\prime \prime}$ & $28^{\circ} 27^{\prime} 32^{\prime \prime}$ & Jules Richard & $19 / 12 / 90$ & $27 / 09 / 91$ & $84,5 \%$ \\
\hline 37 & Foz do Taboão & $53^{\circ} 45^{\prime} 17^{\prime \prime}$ & $28^{\circ} 26^{\prime} 14^{\prime \prime}$ & SIAP & 09/01/91 & $09 / 04 / 94$ & $66,1 \%$ \\
\hline 38 & & & & & $22 / 05 / 94$ & $30 / 04 / 95$ & $93,1 \%$ \\
\hline 51 & Alta Divisa & $53^{\circ} 41^{\prime} 28^{\prime \prime}$ & $28^{\circ} 23^{\prime} 36^{\prime \prime}$ & IH PLG 7S & $28 / 08 / 89$ & & $96,5 \%$ \\
\hline
\end{tabular}

* mesmo local, troca de aparelho e observador

** troca de local, mesmo de aparelho e mesmo observador 
Tabela 3 - Relação dos pluviômetros (Castro et al., 2000)

\begin{tabular}{|c|c|c|c|c|c|c|}
\hline Código & Nome & $\begin{array}{l}\text { Longitude } \\
\text { Oeste }\end{array}$ & $\begin{array}{l}\text { Latitude } \\
\text { Sul }\end{array}$ & $\begin{array}{l}\text { Data } \\
\text { início }\end{array}$ & fim & $\begin{array}{l}\% \text { funcionamento } \\
\text { até } 12 / 98 * *\end{array}$ \\
\hline 13 & Alto Donato & $53^{\circ} 41^{\prime} 14^{\prime \prime}$ & $28^{\circ} 25^{\prime} 06^{\prime \prime}$ & $27 / 06 / 90$ & & $98,8 \%$ \\
\hline 21 & Pejuçara Norte & $53^{\circ} 38^{\prime} 57^{\prime \prime}$ & $28^{\circ} 24^{\prime} 11^{\prime \prime}$ & $06 / 09 / 89$ & $31 / 04 / 96$ & $98,1 \%$ \\
\hline 24 & Turcato Central & $53^{\circ} 40^{\prime} 17^{\prime \prime}$ & $28^{\circ} 24^{\prime} 55^{\prime \prime}$ & $08 / 11 / 89$ & $10 / 05 / 90$ & $84,5 \%$ \\
\hline 32 & Rincão do Jesus & $53^{\circ} 44^{\prime} 34^{\prime \prime}$ & $28^{\circ} 24^{\prime} 52^{\prime \prime}$ & $12 / 12 / 90$ & & $97,4 \%$ \\
\hline 34 & Alto Taboão & $\begin{array}{l}53^{\circ} 36^{\prime} 12^{\prime \prime} \\
53^{\circ} 27^{\prime} 10^{\prime \prime}\end{array}$ & $\begin{array}{l}28^{\circ} 27^{\prime} 21^{\prime \prime} \\
28^{\circ} 26^{\prime} 53^{\prime \prime}\end{array}$ & $\begin{array}{l}17 / 12 / 90 \\
15 / 04 / 97 *\end{array}$ & & $98,6 \%$ \\
\hline 35 & $\begin{array}{l}\text { Velha Estrada } \\
\text { Cruz Alta }\end{array}$ & $53^{\circ} 38^{\prime} 19^{\prime \prime}$ & $28^{\circ} 27^{\prime} 46^{\prime \prime}$ & $17 / 12 / 90$ & & $93,8 \%$ \\
\hline 36 & $\begin{array}{l}\text { Granja da } \\
\text { Castanheiras }\end{array}$ & $53^{\circ} 41^{\prime} 06^{\prime \prime}$ & $28^{\circ} 27^{\prime} 49^{\prime \prime}$ & $01 / 01 / 91$ & & $94,4 \%$ \\
\hline 52 & Baixa Divisa & $53^{\circ} 41^{\prime} 55^{\prime \prime}$ & $28^{\circ} 24^{\prime} 08^{\prime \prime}$ & $07 / 11 / 89$ & & $98,0 \%$ \\
\hline 61 & Santa Lúcia & $\begin{array}{l}53^{\circ} 42^{\prime} 35^{\prime \prime} \\
53^{\circ} 37^{\prime} 13^{\prime \prime}\end{array}$ & $\begin{array}{l}28^{\circ} 23^{\prime} 39^{\prime \prime} \\
28^{\circ} 26^{\prime} 55^{\prime \prime}\end{array}$ & $\begin{array}{l}11 / 11 / 89 \\
02 / 09 / 98^{*}\end{array}$ & & $99,7 \%$ \\
\hline 62 & $\begin{array}{l}\text { Granja Santa } \\
\text { Catarina }\end{array}$ & $53^{\circ} 43^{\prime} 37^{\prime \prime}$ & $28^{\circ} 25^{\prime} 04^{\prime \prime}$ & $23 / 10 / 90$ & 08/06/92 & $95,4 \%$ \\
\hline
\end{tabular}

* troca de local e observador

** \% da duração das observações aproveitáveis em relação a duração total

Tabela 4 - Características gerais dos linígrafos (Castro et al., 2000)

\begin{tabular}{|c|c|c|c|c|c|c|c|}
\hline \multirow[t]{2}{*}{ Código } & \multirow[t]{2}{*}{ Nome } & \multicolumn{2}{|l|}{ Data } & \multirow{2}{*}{$\begin{array}{l}\% \text { funcionamento } \\
\text { até dez } / 98\end{array}$} & \multirow[t]{2}{*}{ Marca } & \multicolumn{2}{|c|}{ Aparelho } \\
\hline & & Início & Fim & & & Tipo & redução \\
\hline 01 & Donato & $11 / 11 / 89$ & - & 83,0 & $\mathrm{IH}$ & LNG7 & $1 / 10$ \\
\hline \multirow[t]{2}{*}{02} & Turcato & $11 / 11 / 89$ & $10 / 10 / 95$ & 73,9 & $\mathrm{IH}$ & LNG7 & $1 / 10$ \\
\hline & & $22 / 07 / 98$ & & 96,3 & $\mathrm{IH}$ & LNG7 & $1 / 10$ \\
\hline 03 & Taboão & $20 / 12 / 90$ & $29 / 10 / 91$ & - & OTT & $\mathrm{R} 20$ & $1 / 10$ \\
\hline \multirow[t]{2}{*}{04} & Andorinhas & $10 / 11 / 89$ & $30 / 10 / 91$ & - & OTT & 10 & $1 / 10$ \\
\hline & & $30 / 10 / 91$ & $25 / 05 / 92$ & & OTT & $\mathrm{R} 20$ & $1 / 10$ \\
\hline 06 & Rincão & $09 / 01 / 91$ & 06/04/92 & - & $\mathrm{IH}$ & LNG7 & $1 / 10$ \\
\hline 07 & Anfiteatro & $23 / 07 / 92$ & - & 78,2 & $\mathrm{IH}$ & LNG7 & $1 / 5$ \\
\hline
\end{tabular}

Além do linígrafo e da régua linimétrica, a estação foi equipada de uma instalação de medição de vazão por teleférico.

O conjunto da estação ficou submerso em 26 e 27 de maio de 1992, quando o nível da água atingiu $680 \mathrm{~cm}$ que é uma altura superior ao nível do próprio linígrafo. No entanto, poucos danos foram constatados e, depois de uma limpeza, o linígrafo voltou a funcionar no início de julho de 1992.

No dia 12/12/95, o linígrafo desta bacia foi retirado por problemas de funcionamento. Com um financiamento do projeto pela FINEP foi possível restaurar o posto. Um linígrafo mecânico foi colocado no dia 24/07/98. Foram ajustadas duas curvas chaves para a seção: a primeira válida de 1990 a dezembro de 1995 e a segundo a partir de agosto de 1998. Para a primeira curva, foram realizadas 62 medições de vazão na estação fluviométrica do Arroio Turcato entre as cotas $30 \mathrm{~cm}$ e $201 \mathrm{~cm}$. A seção medida era razoavelmente estável no momento da elaboração da curva-chave.
O nível de enchente dos dias 26 e 27 de maio de 1992, avaliado a partir das marcas deixadas, foi estimado em $680 \mathrm{~cm}$. Foi então necessário extrapolar a curva-chave, e o método de Stevens (Chevallier, 1993) foi utilizado. A extrapolação foi prolongada para avaliar a descarga atingida no topo da cheia do dia 27 de maio de 1992. A vazão na cota de $680 \mathrm{~cm}$ ficou em aproximadamente $20 \mathrm{~m}^{3} / \mathrm{s}$.

Entre agosto e dezembro de 1998 foram realizadas 30 medições de vazão na estação fluviométrica do Arroio Turcato entre as cotas 40 e $312 \mathrm{~cm}$, resultando em uma nova curva-chave, válida a partir de agosto de 1998. $O$ perfil transversal praticamente não modificou-se nas margens dentro da calha, somente aprofundou, em relação ao perfil médio adotado anteriormente. Fora da calha, a seção transversal permaneceu a mesma. A cota máxima observada e, felizmente, medida, foi de $319 \mathrm{~cm}$ no dia $18 / 09 / 98$ às $03 \mathrm{~h} 09 \mathrm{~min}$. Somente quando o nível do rio extravasa a calha, é necessário extrapolar, utilizando para isso o método de Stevens. A curva-chave foi extrapolada até a cota $500 \mathrm{~cm}$. 


\section{ANÁLISE DAS PRECIPITAÇÕES DOS DOIS PERÍODOS DE PLANTIO}

Os dados pluviométricos foram analisados visando identificar os processos que ocorreram nas três bacias embutidas durante o período com dados disponíveis de 1989 a 1999. Segundo Silva Júnior (2001), os dados de precipitação da região permitiram observar o seguinte:

- A variabilidade espacial da precipitação anual no período em estudo (1989-1999) pode ser considerada pequena;

- A média das precipitações anuais do período de 1989-1998 (1.849 mm) em relação ao período de 1960-1997 (1.692 mm) é um pouco maior (10\%); a variabilidade temporal da precipitação anual no período em estudo foi grande devido à ocorrência do fenômeno ENSO no ano hidrológico de 1997 que provocou o ano mais úmido $(2.761 \mathrm{~mm})$ dos últimos 50 anos precedido do ano mais seco (1.414 $\mathrm{mm}$ ) no período de estudo. Assim o período de plantio direto se caracteriza por uma variância alta quando comparada com a do período de plantio convencional;

- O período de plantio direto (1994-1998) apresenta anos hidrológicos com precipitações anuais abaixo da média do período total, com exceção do ano de 1997, que, por ser extremamente úmido, fez com que as médias dos dois períodos fossem similares. Logo, apesar dos períodos convencional e plantio direto terem médias equivalentes (1863 e $1836 \mathrm{~mm}$, respectivamente), podemos considerar o período de plantio direto como o mais seco;

- A variabilidade temporal das precipitações mensais se caracteriza pela ocorrência do fenômeno ENSO que provocou valores extremos (outliers) nos meses de maio de 1992 e outubro de 1997. Sem a interferência do ENSO, a distribuição interanual das precipitações é bastante uniforme, variando entre 116 $\mathrm{mm}$ (março) a $167 \mathrm{~mm}$ (outubro), no período 19891999;

- A precipitação máxima diária apresentou valores extremos nos anos de 1992 (241,6 mm) e 1997 (151,6 mm) devido ao efeito do ENSO, sendo que o ano de 1992 pode ser considerado como outlier, não devendo ser considerado nos estudos.

\section{VAZÕES MÁXIMAS}

As vazões máximas são variáveis de fácil caracterização no hidrograma. Através dos eventos registrados nas bacias embutidas do Potiribu foram obtidos os valores das vazões máximas de cada bacia, utilizando séries parciais devido à existência de poucos anos de dados.

\section{Vazões máximas instantâneas}

Para estabelecer a distribuição de valores máximos em uma série parcial é necessário escolher uma vazão Qo acima da qual a vazão é selecionada. A escolha desta vazão é subjetiva, neste trabalho foram adotados os seguintes critérios (NERC, 1975):

- A vazão Qo deve permitir a seleção de, pelo menos, 3 a 4 valores por ano, sendo adotado o mesmo valor em ambos períodos em análise;

- As vazões máximas devem ser independentes entre si. Os valores de vazão máxima foram considerados independentes (Qp*) quando, entre dois valores de vazão máxima (Qp), a vazão (Q) baixar para menos de 15\%

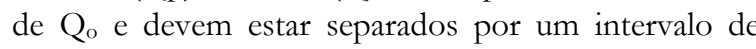
tempo $(\Delta \mathrm{t})$ maior que 20 vezes o tempo de pico (tp) do primeiro hidrograma.

A metodologia apresentada na referência citada utiliza uma distribuição exponencial onde a razão de excedência $(L)$ é dada pelo número de picos que excedem Q $(M)$ dividido pelo número de anos da série registrada $(N)$. Essa razão $(L)$ é usada para corrigir o tempo de retorno dos picos, pois não foi escolhido um pico por ano e sim, em média, $L$ pico por ano. Sendo a distribuição dos picos considerada como exponencial, logo:

$$
\mathrm{P}\left(\mathrm{Q} \geq \mathrm{Q}_{\mathrm{i}} / \mathrm{Q}_{\mathrm{i}} \geq \mathrm{Q}_{\mathrm{o}}\right)=\mathrm{e}^{-\left(\mathrm{Q}-\mathrm{Q}_{\mathrm{o}}\right) / \mathrm{B}}
$$

onde o parâmetro $B$ é estimado por:

$$
\mathrm{B}=\frac{1}{\mathrm{M}} \sum_{\mathrm{i}=1}^{\mathrm{M}}\left(\mathrm{Q}_{\mathrm{i}}-\mathrm{Q}_{\mathrm{o}}\right)
$$

A vazão máxima em função do tempo de retorno é obtida através de:

$$
\mathrm{Q}(\mathrm{Tr})=\mathrm{Q}_{\mathrm{O}}+\mathrm{B} \cdot[\ln (\mathrm{L})+\ln (\mathrm{Tr})]
$$

A vazão média de cheia $\left(\mathrm{Q}_{\mathrm{mx}}\right)$ fica :

$$
\mathrm{Q}_{\mathrm{mx}}=\mathrm{Q}_{\mathrm{o}}+\mathrm{B} \cdot[\ln (\mathrm{L})+0,5772]
$$

A Tabela 5 apresenta as estatísticas das séries parciais de vazões máximas determinadas para as bacias embutidas do Potiribu. Na tabela, também é apresentada a vazão específica média de cheia de cada bacia. Utilizando o teste F (Benjamin e Cornell, 1970) para as variâncias das séries de vazões máximas para cada período de uso específico do solo, verificou-se que a variância no período de plantio direto é maior que a variância no plantio conven 
Tabela 5 - Estatística das séries parciais de vazão máxima

\begin{tabular}{|c|c|c|c|c|c|c|c|c|c|}
\hline \multirow{3}{*}{$\begin{array}{l}\text { Período de Plantio } \\
\text { Valores da série }\end{array}$} & \multicolumn{3}{|c|}{ Anfiteatro } & \multicolumn{4}{|l|}{ Donato } & \multicolumn{2}{|c|}{ Turcato } \\
\hline & \multirow{2}{*}{$\begin{array}{l}\text { Conv. }{ }^{1} \\
\text { sem } \\
\text { ENSO }\end{array}$} & \multicolumn{2}{|l|}{ Direto } & \multicolumn{2}{|c|}{ Convencional } & \multicolumn{2}{|l|}{ Direto } & \multirow{2}{*}{$\begin{array}{l}\text { Conv. }{ }^{1} \\
\text { sem } \\
\text { ENSO }\end{array}$} & \multirow{2}{*}{$\begin{array}{l}\text { Direto } \\
\text { sem } \\
\text { ENSO }\end{array}$} \\
\hline & & $\begin{array}{l}\text { com } \\
\text { ENSO }\end{array}$ & $\begin{array}{l}\text { sem } \\
\text { ENSO }\end{array}$ & $\begin{array}{l}\text { com } \\
\text { ENSO }\end{array}$ & $\begin{array}{l}\text { sem } \\
\text { ENSO }\end{array}$ & $\begin{array}{l}\text { com } \\
\text { ENSO } \\
\end{array}$ & $\begin{array}{l}\text { sem } \\
\text { ENSO }\end{array}$ & & \\
\hline No. de anos $(N)$ & 3 & 6 & 5 & 3 & 3 & 6 & 5 & 5 & 4 \\
\hline No. de eventos $(M)$ & 23 & 15 & 12 & 17 & 16 & 15 & 10 & 21 & 12 \\
\hline$L(M / N)$ & 7,67 & 2,50 & 2,40 & 5,67 & 5,33 & 2,50 & 2,00 & 4,20 & 3,0 \\
\hline $\operatorname{Máximo~}\left(\mathrm{m}^{3} / \mathrm{s}\right)$ & 1,15 & 0,84 & 0,50 & 28,27 & 17,11 & 11,26 & 2,91 & 12,60 & 36,09 \\
\hline Mínimo $\left(\mathrm{m}^{3} / \mathrm{s}\right)$ & 0,04 & 0,03 & 0,03 & 0,62 & 0,62 & 0,70 & 0,74 & 5,26 & 5,60 \\
\hline$Q_{\mathrm{o}}\left(\mathrm{m}^{3} / \mathrm{s}\right)$ & 0,03 & 0,03 & 0,03 & 0,50 & 0,50 & 0,50 & 0,50 & 5,00 & 5,00 \\
\hline Média $\left(\mathrm{m}^{3} / \mathrm{s}\right)$ & 0,22 & 0,25 & 0,12 & 5,23 & 3,79 & 3,05 & 1,51 & 7,84 & 10,91 \\
\hline Desvio padrão $\left(\mathrm{m}^{3} / \mathrm{s}\right)$ & 0,27 & 0,30 & 0,14 & 7,66 & 5,00 & 3,41 & 0,82 & 1,94 & 8,17 \\
\hline Média de cheia ${ }^{2}\left(\mathrm{~m}^{3} / \mathrm{s}\right)$ & 0,52 & 0,36 & 0,16 & 11,43 & 7,91 & 4,30 & 1,78 & 10,72 & 14,91 \\
\hline $\begin{array}{l}\text { Média de Cheia específica } \\
\left(\mathrm{m}^{3} / \mathrm{s} / \mathrm{km}^{2}\right)\end{array}$ & 4,13 & 2,84 & 1,29 & 10,40 & 7,19 & 3,91 & 1,62 & 0,55 & 0,76 \\
\hline
\end{tabular}

1 - Período sem registro do ENSO

2 - Valor obtido pela Equação 5

cional para a bacia do Turcato e menor para as demais bacias para o nível de significância de 5\%.

As médias de cheia do período convencional nas bacias do Anfiteatro e Donato são maiores do que as respectivas médias no período de plantio direto para o nível de significância de $1 \%$. Ao contrário do observado nas bacias do Anfiteatro e do Donato, na bacia do Turcato, a média de cheia do período de plantio direto é maior do que a média de cheia no período convencional para o nível de significância de $5 \%$.

Analisando as vazões máximas adimensionalizadas pela média no período de plantio convencional nas bacias embutidas do Potiribu verificou-se que as séries de vazões adimensionalizadas do Donato com e sem os valores sob efeito do ENSO são praticamente coincidentes, mostrando que o efeito do ENSO foi de aumentar a média da série nesse período.

$\mathrm{Na}$ análise seguinte, foram utilizadas somente as séries sem o ENSO. A distribuição estatística das vazões máximas adimensionais mostrou que, para todas as bacias, ocorreu aumento da vazão máxima adimensional para o plantio direto, sendo 23,8 \% no Anfiteatro, 14,9\% no Donato e $15,6 \%$ no Turcato.

Na Figura 3, é apresentado o resultado para a bacia do Donato, que é semelhante ao resultado das outras bacias. Na tabela 5, são apresentados os valores das vazões médias máximas e observa-se uma redução da vazão média de cheia para o plantio direto no Anfiteatro e Donato, respectivamente de 31 e $22,5 \%$, mas para o Turcato ocorre aumento de $39 \%$.

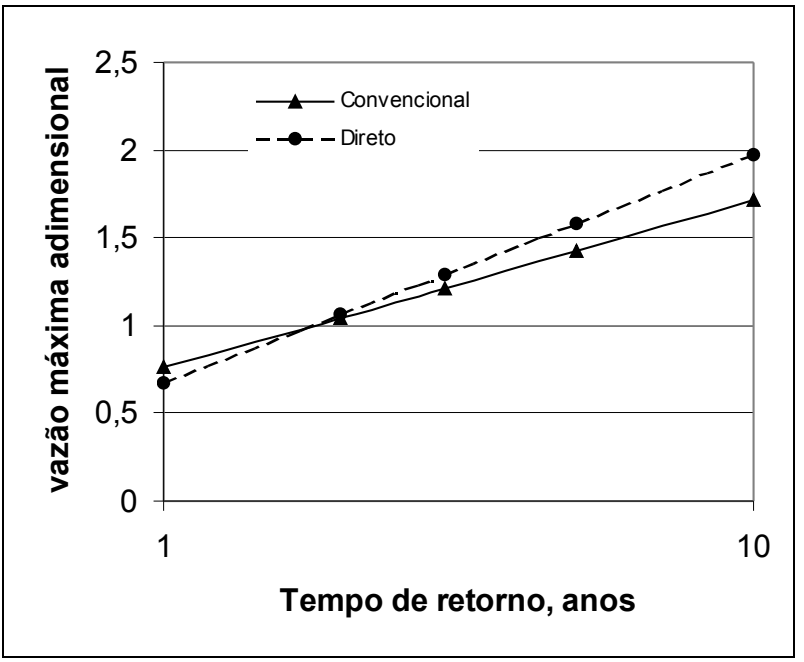

Figura 3 - Vazões máximas adimensionais no Donato para os dois cenários.

Observa-se assim que o plantio direto mostra maior dispersão com relação à média em todas as escalas de bacia estudadas, mas em valores médios máximos absolutos observa-se uma transição de resultados, pois nas duas primeiras escalas de bacia ocorre redução da vazão máxima média no plantio direto, mas na escala do Turcato ocorre aumento da vazão máxima média. O aumento do escoamento na escala maior pode ser decorrência da distância de contribuição do escoamento subsuperficial nas bacias de cabeceiras. No plantio direto, a maior infiltração aumentou o escoamento sub-superficial e a contribuição para o freático, que não aparece no exutório das bacias pequenas (Anfiteatro e Donato) devido a pequena distância, mas que contribui mais a jusante para as bacias maiores, como o observado na bacia do Turcato. 
Volumes dos eventos de cheia

Com base nos registros de vazão e precipitação das bacias embutidas do Potiribu foram escolhidos 403 eventos, sendo que 106 eventos são referentes à bacia do Anfiteatro (38 no período de plantio convencional e 68 no plantio direto), 126 ocorreram na bacia do Donato (69 no período de plantio convencional e 57 no plantio direto) e 171 registrados na bacia do Turcato (103 no período de plantio convencional e 68 no plantio direto).

Cada evento consiste da precipitação total $\left(\mathrm{P}_{\text {total }}\right)$ e do hidrograma correspondente de cada bacia. Para melhor caracterização dos hidrogramas, foram identificadas as seguintes variáveis dos hidrogramas: as vazões inicial, final e de pico ( $\mathrm{Q}_{\text {ini, }}, \mathrm{Q}_{\text {final }}$ e $\mathrm{Q}_{\mathrm{p}}$, respectivamente) e os tempos de pico e de base ( $t_{p}$ e $\left.t_{b}\right)$. Nos hidrogramas selecionados, foi realizada a separação do escoamento superficial do subterrâneo pelo método gráfico direto baseado em dois pontos (Tucci, 1993), sendo que o escoamento sub-superficial, foi considerado junto com o escoamento superficial para compor o volume de cheia. Os pontos do método gráfico foram determinados por inspeção visual do hidrograma numa escala mono-log.

Precipitação e escoamento superficial dos eventos de cheia

A relação foi utilizada para analisar o comportamento das inundações nos cenários de plantios para as diferentes bacias.

$\mathrm{Na}$ figura 4, observa-se grande dispersão dos pontos observados com relação à tendência central para os valores observados na bacia do Anfiteatro no período de plantio convencional. Essa dispersão diminui visivelmente no período de plantio direto, como podemos observar na figura 5. A maior uniformidade da geração do escoamento superficial no período de plantio direto não se deve ao regime de precipitação desse período, pois os regimes de precipitação nos períodos não apresentam diferenças significativas, mas refere-se a uma resposta hidrológica da mudança de uso do solo.

Comportamento semelhante é observado também para as outras bacias maiores (Donato e Turcato). Também se observa nas figuras 6 e 7 que na maior bacia (Turcato), os valores têm menor dispersão no plantio convencional. Quanto maior a bacia, mais uniforme é a distribuição das observações em relação à tendência central e que o período de plantio direto também apresenta uma distribuição mais uniforme que a do plantio convencional.

O período de plantio direto mostrou ser mais regular, com menor variabilidade das condições iniciais, em relação ao período convencional, devido a uma maior uniformidade da cobertura vegetal e umidade do solo no plantio direto em relação ao convencional. A umidade do solo se mantém mais constante no plantio direto em rela- ção ao convencional porque este tipo de plantio favorece a infiltração e diminui e a evaporação da água retida no solo, por manter uma cobertura vegetal constante.

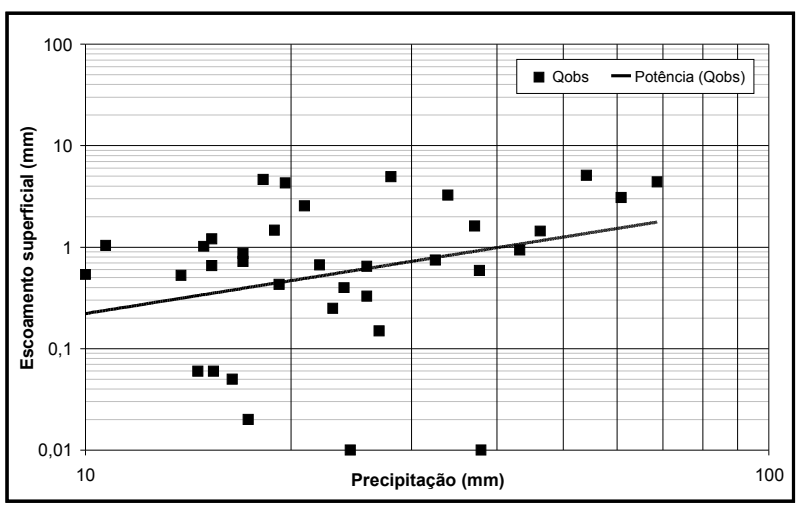

Figura 4. Precipitação e escoamento superficial no Anfiteatro durante o plantio convencional.

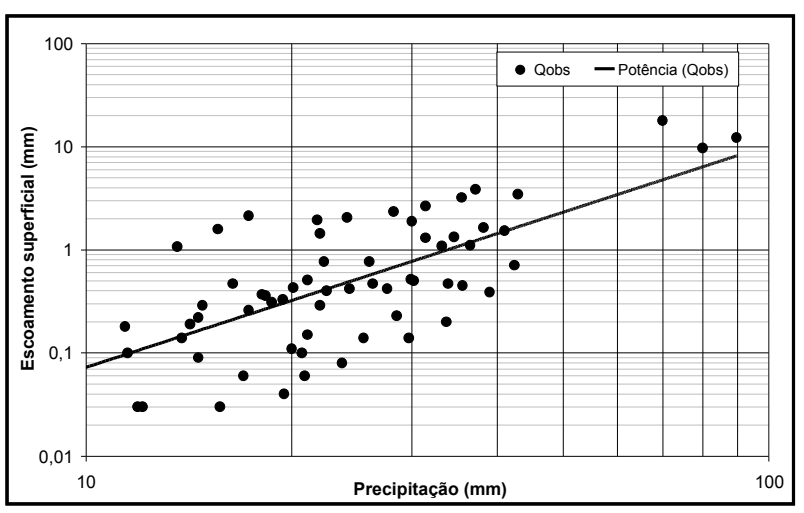

Figura 5. Precipitação e escoamento superficial no Anfiteatro durante o plantio direto.

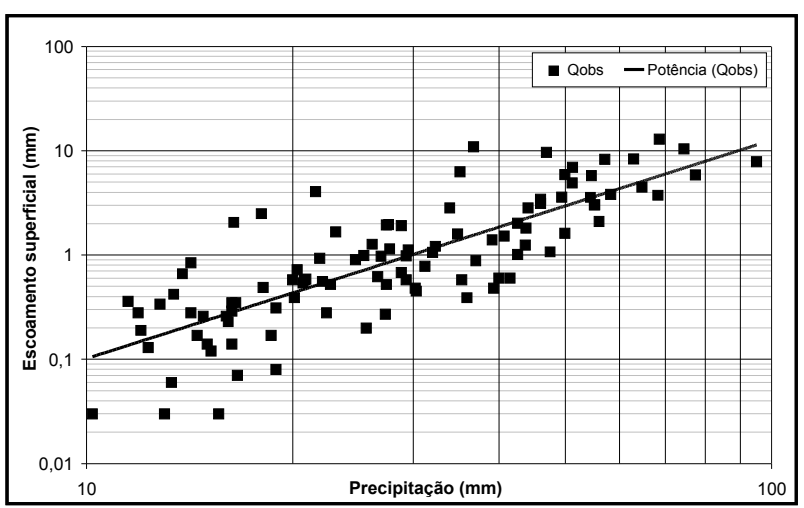

Figura 6. Precipitação e escoamento superficial no Turcato durante o plantio convencional.

$\mathrm{Na}$ figura 8, pode-se observar a comparação das tendências médias desta relação para o Anfiteatro nos períodos de plantio convencional e plantio direto. Pela figura, verificamos que o ajuste do período convencional 
gera mais escoamento do que o do período de plantio direto para pequenas precipitações (menores que $30 \mathrm{~mm}$ ), contudo, para grandes precipitações, é o ajuste do plantio direto que fornece escoamentos maiores.

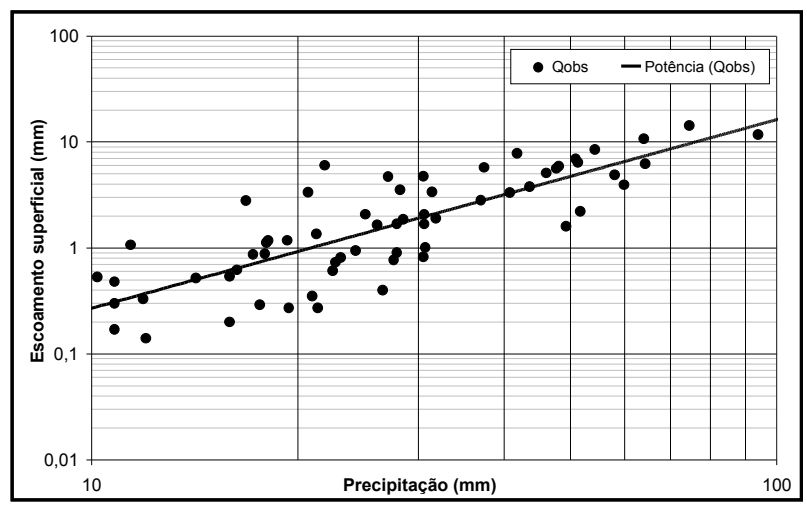

Figura 7. Precipitação e escoamento superficial no Turcato durante o plantio direto.

A figura 9 mostra que, na bacia do Donato, a tendência do período de plantio convencional gera mais escoamento do que o do plantio direto. Contudo, essa tendência se inverte para precipitações maiores que $60 \mathrm{~mm}$.

$\mathrm{Na}$ bacia do Turcato a tendência no plantio direto gera mais escoamento para precipitações menores que 100 $\mathrm{mm}$ (figura 10).

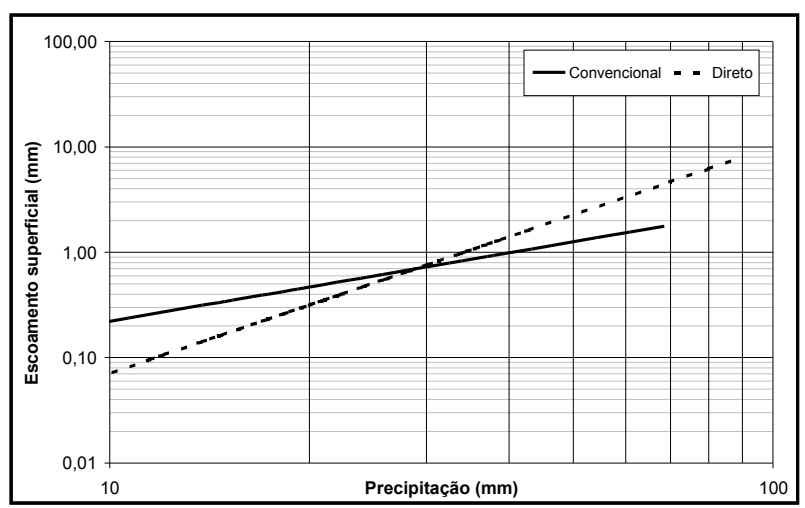

Figura 8 Tendência média do escoamento superficial na bacia do Anfiteatro

$\mathrm{Na}$ figura 11 verifica-se que no plantio convencional, quando $\mathrm{P}>30 \mathrm{~mm}$ o escoamento aumenta com o tamanho da bacia. Uma possível explicação para esse fato seria a alta capacidade de armazenamento do solo que absorveria a precipitação até $30 \mathrm{~mm}$ com pouco escoamento sub-superficial (em termos médios) passando a existir percolação para o freático e forte escoamento subsuperficial somente acima desse valor. O escoamento subsuperficial afloraria mais a jusante, nas bacias maiores, como a do Turcato.

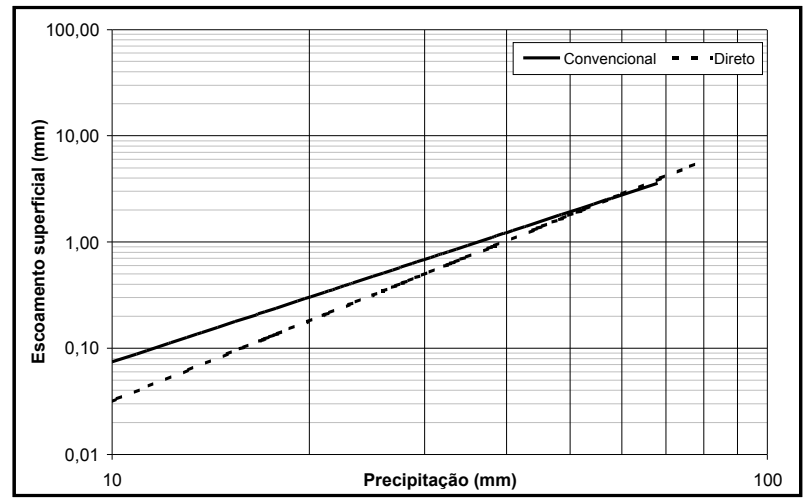

Figura 9. Tendência média do escoamento superficial na bacia do Donato

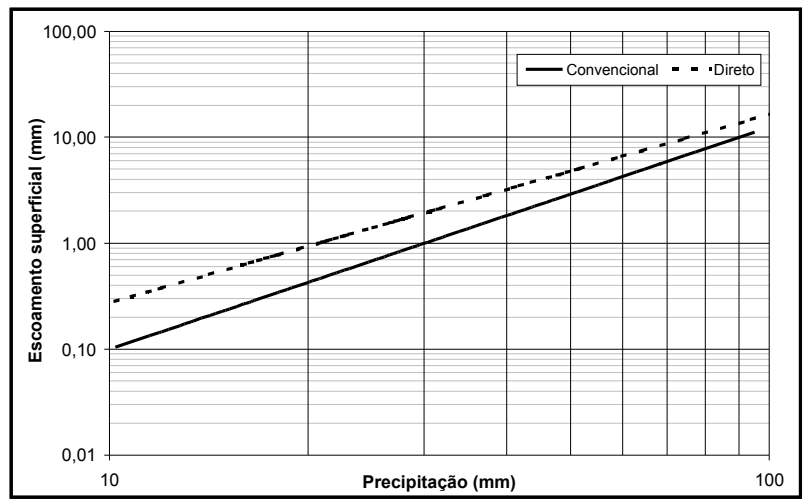

Figura 10 Tendência média do escoamento superficial na bacia do Turcato

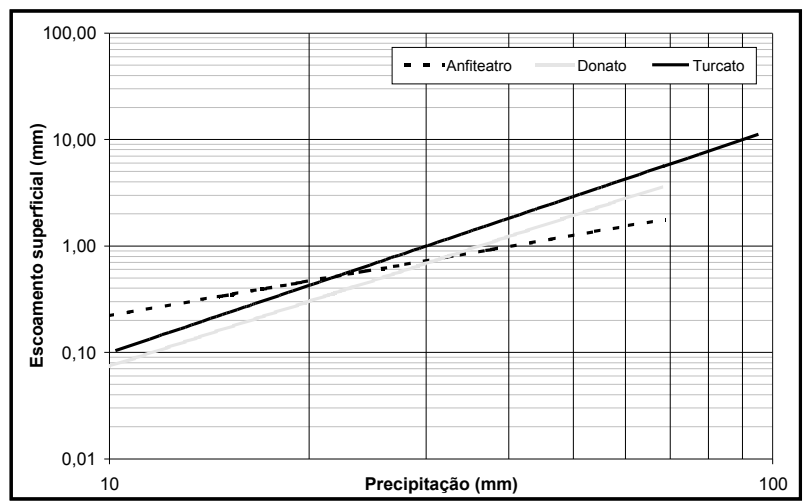

Figura 11 Tendência média do escoamento superficial no período de plantio convencional

$\mathrm{Na}$ figura 12, não existe uma tendência relacionada com o tamanho da bacia, mas Turcato produz mais escoamento. Estas tendências não explicam todo o comportamento deste processo já que a variabilidade ocorrida depende da umidade do solo antecedente e de sua distribuição ao longo do evento, mas permite analisar uma tendência geral para os eventos ocorridos e para as características das bacias e uso do solo. 
O comportamento das bacias para o plantio convencional foi o esperado (quanto maior a área da bacia, maior o escoamento para precipitações acima de $30 \mathrm{~mm}$ ), enquanto que para o plantio direto mostra que na medida que a bacia cresce diminui o escoamento superficial, mas ocorre uma transição de escala entre Donato $\left(1 \mathrm{~km}^{2}\right)$ e Turcato ( $19 \mathrm{~km}^{2}$ ) em que o efeito do comprimento de escoamento do sub-superficial que escoa para os canais aumenta o escoamento superficial.

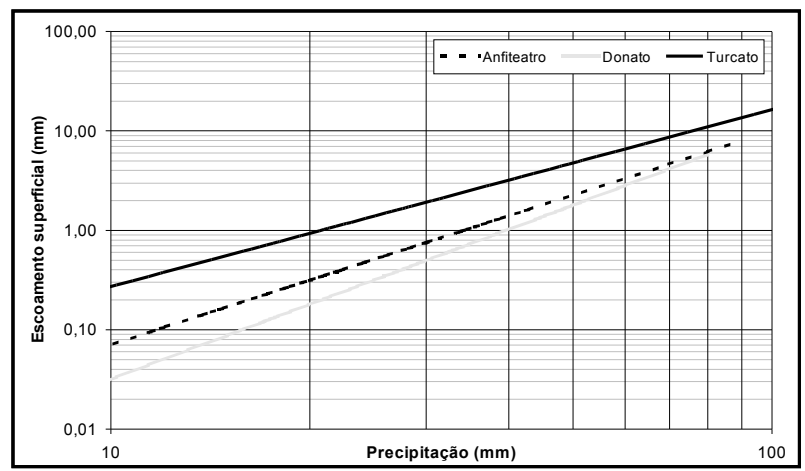

Figura 12 - Tendência média do escoamento superficial no período de plantio direto

Relação entre a vazão de pico e o coeficiente de escoamento

O coeficiente de escoamento de um evento de inundação retrata a parcela de escoamento superficial. À medida que a vazão máxima aumenta existe a tendência do coeficiente aumentar. Esta relação permite compreender também as inundações nas diferentes bacias e suas tendências.

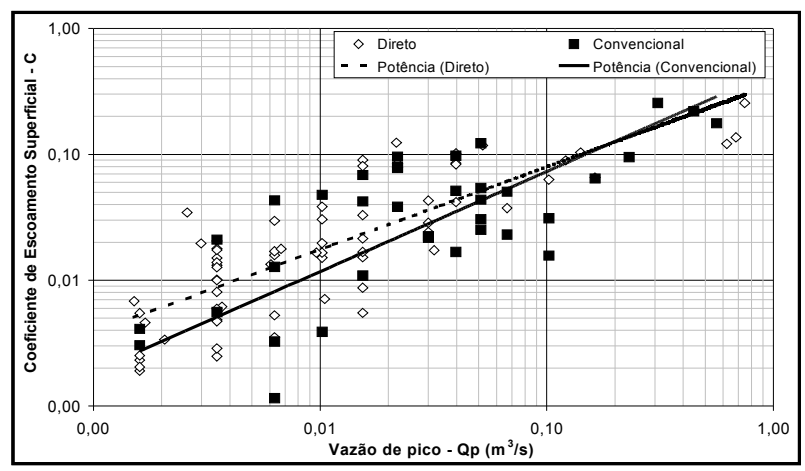

Figura 13 Relação entre vazão de pico $Q_{p}$ e coeficiente de escoamento superficial C no Anfiteatro

A figura 13 apresenta os valores dos dois cenários para a bacia do Anfiteatro. A tendência média mostra que no plantio direto o mesmo coeficiente de escoamento produz um menor pico. Na figura 14 , na bacia do Donato, as tendências são semelhantes, mas a dispersão com rela- ção à tendência média é menor. Na figura 15 , na bacia do Turcato, a dispersão com relação à tendência média é ainda menor, mas a relação entre os plantios se mantém.

Nas figuras 16 e 17, são comparadas estas relações para as três bacias (nos dois períodos), onde se observa que as duas bacias menores apresentam tendências quase coincidentes, enquanto que Turcato apresenta menor valor de pico para o mesmo coeficiente de escoamento, resultado esperado devido ao amortecimento das inundações.

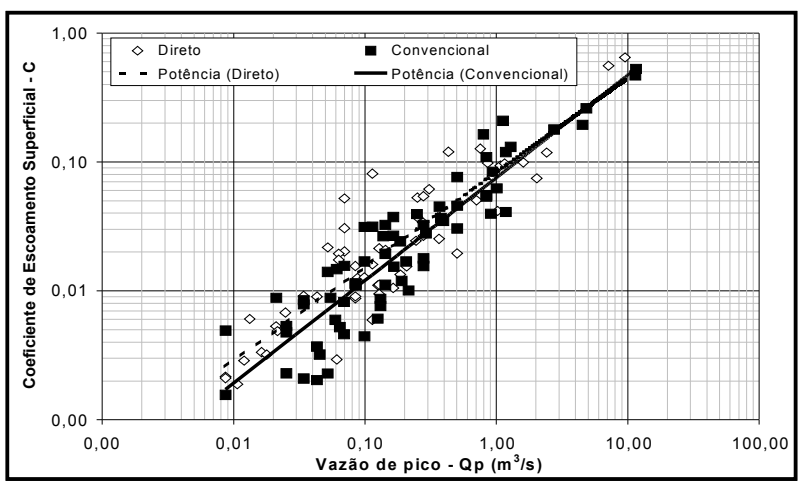

Figura 14 Relação entre vazão de pico $Q_{p}$ e coeficiente de escoamento superficial C no Donato

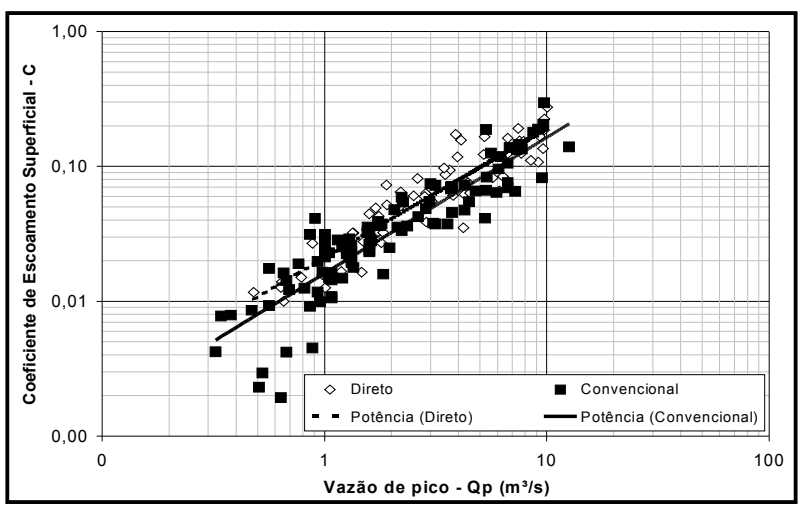

Figura 15 Relação entre vazão de pico $Q_{p}$ e coeficiente de escoamento superficial $\mathrm{C}$ no Turcato

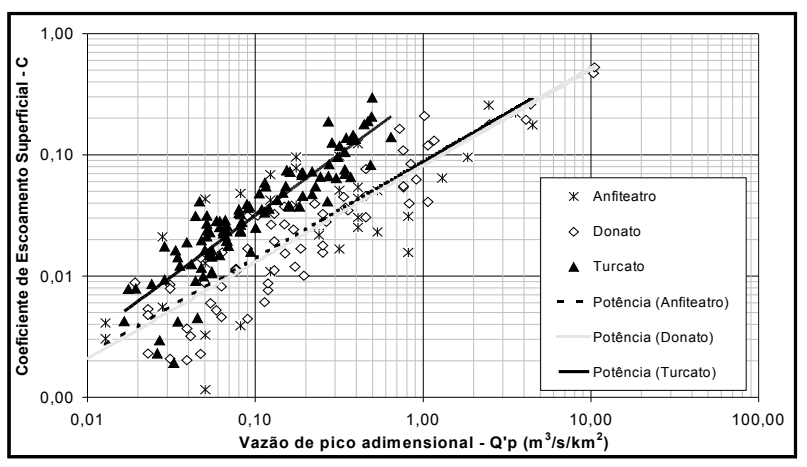

Figura 16 Relação entre vazão de pico adimensional $Q_{p}^{\prime}$ e C no período de plantio convencional 


\section{Estudo de eventos de cheia simultâneos} nas três bacias

Para uma melhor compreensão dos eventos de inundação nos dois períodos foram escolhidos os mesmos eventos nas três bacias (num total de 20) nos dois cenários de plantio, convencional e direto.

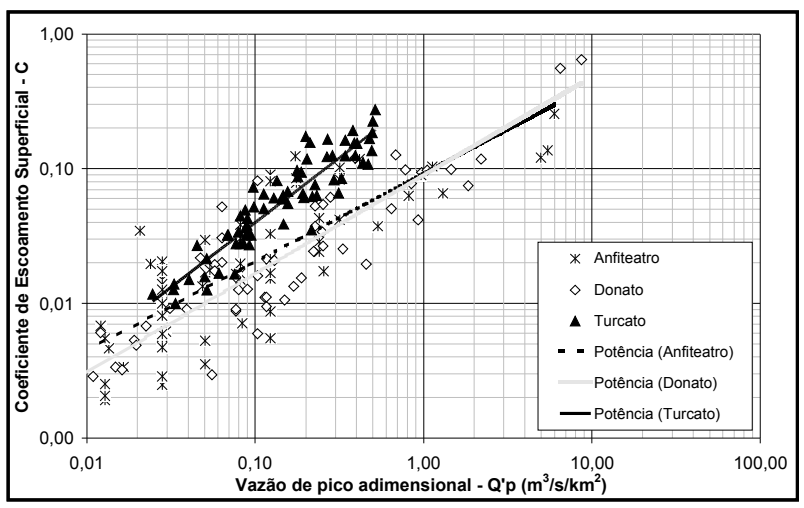

Figura 17 Relação entre vazão de pico adimensional Q'p e C no período de plantio direto

Esses eventos simultâneos apresentam a vantagem de mostrar a resposta hidrológica das bacias para o mesmo evento. Evidentemente, a precipitação apresentou uma pequena variação espacial, o que resultou numa condição pluviométrica ligeiramente diferente para as três bacias.

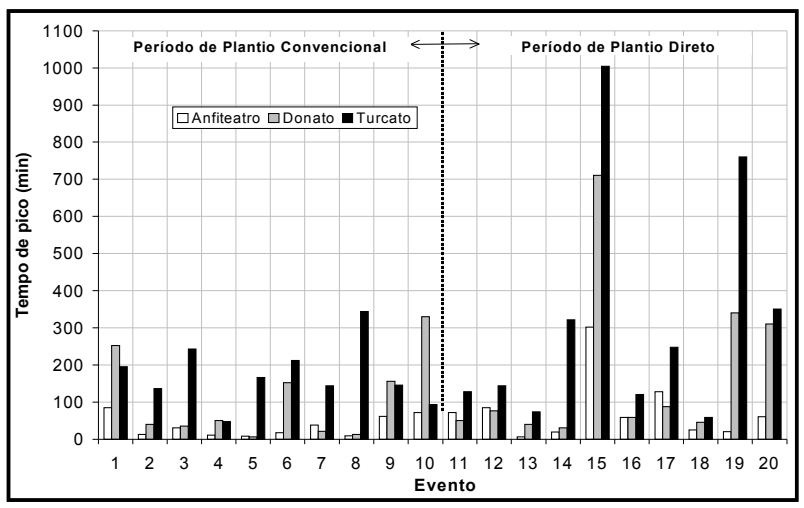

Figura 18. Comparação do tempo de pico dos 20 eventos selecionados

A Figura 18 apresenta o tempo de pico dos hidrogramas observados nas bacias embutidas do Potiribu, nos 20 eventos selecionados. As relações permanentes de tempo de pico são explicadas pelo tipo e uso de solo enquanto que as diferenças esporádicas são explicadas pela variabilidade espacial e temporal da precipitação. Como estes efeitos estão combinados em cada evento nas três bacias, foi analisada a moda de tendência de magnitude entre eles para diferenciar os períodos de plantio. O cená- rio esperado para os dois tipos de plantio é de aumento do tempo de pico para aumento da área da bacia. Observa-se que isto ocorre em $50 \%$ dos eventos no plantio convencional e $70 \%$ no plantio direto.

Para as vazões máximas específicas (Figura 19) observa-se que no plantio convencional existe predominância $(80 \%)$ da seguinte seqüência: maior vazão máxima específica para a bacia menor (Anfiteatro), seguida da maior bacia (Turcato) e finalmente a intermediária (Donato).

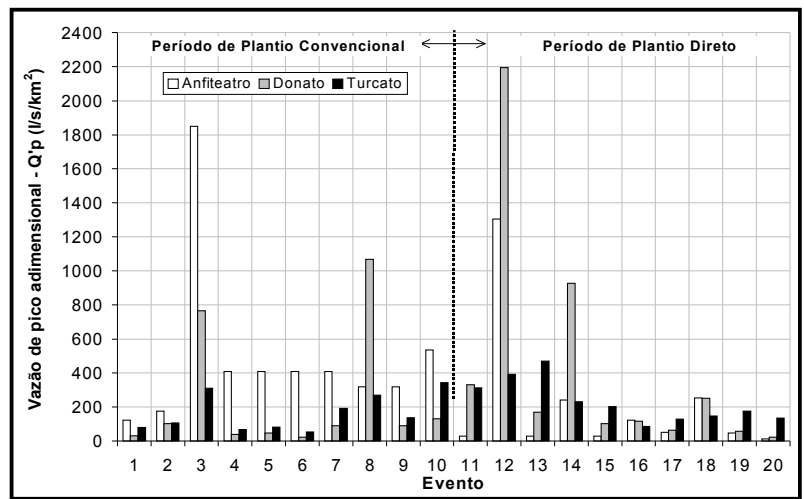

Figura 19. Comparação da vazão máxima específica dos 20 eventos selecionados

O esperado seriam vazões específicas decrescentes com o tamanho da bacia. No entanto, isto pode ser explicado pelas outras características de uso do solo e declividade. $\mathrm{Na}$ análise relativa, observa-se que no plantio direto, não houve predominância de nenhuma tendência nos eventos ocorridos e a vazão específica variou entre diferentes combinações. Este efeito pode ser devido à pequena variabilidade das precipitações, mas é nítida a redução da vazão específica máxima da menor bacia para o plantio direto.

A figura 20 apresenta o volume escoado nos eventos selecionados. No cenário de plantio convencional observa-se que a bacia de vertente apresenta volumes equivalentes ou maiores que o Turcato e maiores que Donato em $90 \%$ do tempo. No plantio direto houve mudança de tendência, com redução do escoamento superficial na vertente e aumento com o tamanho das bacias, principalmente no Turcato (maior bacia), como identificado anteriormente.

Nas figuras 21 e 22 podem ser observados dois eventos característicos destes dois períodos, onde os valores são as vazões específicas das bacias. Nessas figuras, observa-se a diferença de magnitude das vazões específicas das bacias nos dois períodos de plantio, principalmente na bacia do Anfiteatro, cujo hidrograma é amortecido no período de plantio direto, tornando-se similar ao da bacia do Donato. 


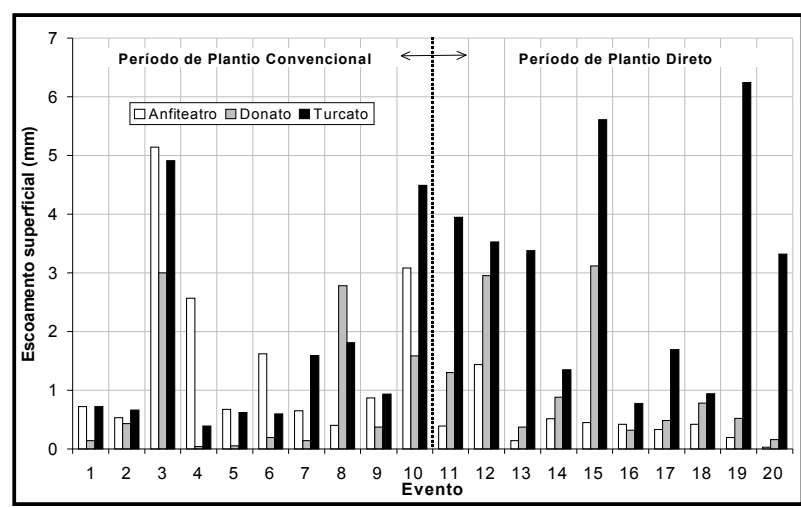

Figura 20. Comparação do volume escoado dos 20 eventos selecionados

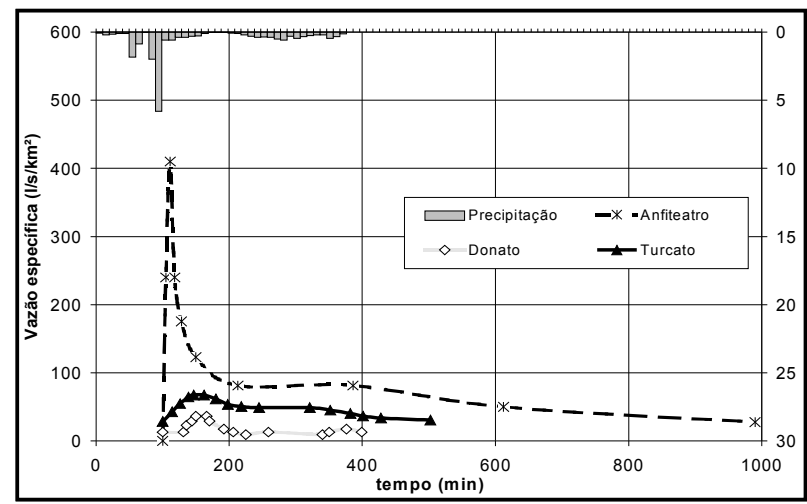

Figura 21 Vazão específica das bacias do Potiribu, no dia 18/09/92 (plantio convencional)

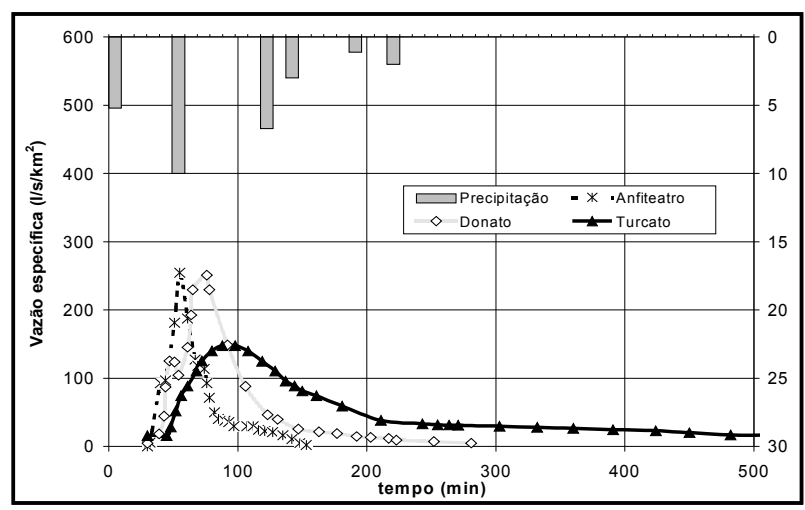

Figura 22 Vazão específica das bacias do Potiribu no dia 16/02/99 (Plantio Direto)

\section{CONCLUSÕES}

A análise dos eventos de cheia ocorridos nas bacias embutidas do rio Potiribu nos períodos convencional (1989-1994) e de plantio direto (1994-1999) mostrou o efeito da mudança do tipo de plantio nas seguintes variáveis hidrológicas: vazão máxima; volume e coeficiente de escoamentos. Neste artigo, procurou-se averiguar a influência da escala hidrológica nos efeitos devidos à mudança de plantio, que revelou que a sub-bacia de vertente $(0,125$ $\mathrm{km}^{2}$ ) tem pequena regularização e comportamento diferenciado das demais.

Observou-se, nos valores medidos, que com o plantio direto houve redução nos picos de cheia das bacias menores $\left(0,125 \mathrm{~km}^{2}\right.$ e $\left.1,10 \mathrm{~km}^{2}\right)$ e aumento na bacia maior $\left(19,50 \mathrm{~km}^{2}\right)$. No período de plantio direto foi observada uma resposta hidrológica (escoamento superficial) mais uniforme do que no período de plantio convencional. Em eventos observados no plantio convencional, a menor bacia $\left(0,125 \mathrm{~km}^{2}\right)$ produz vazões específicas maiores que as demais, como era de se esperar, porém, em eventos observados no plantio direto, é a bacia intermediária $\left(1,10 \mathrm{~km}^{2}\right)$ que gera as maiores vazões específicas.

Em síntese, as conclusões referentes à mudança de plantio convencional para plantio direto nas bacias embutidas do rio Potiribu foram:

- A bacia do Anfiteatro é muito pequena $\left(0,125 \mathrm{~km}^{2}\right)$ para ser considerada como uma bacia hidrográfica propriamente dita, pois parte significativa do escoamento subsuperficial gerado pela infiltração nessa bacia produz escoamento superficial fora da bacia, mais a jusante, nas bacias maiores (Donato e Turcato), de forma que não podemos mais quantificá-los como originários dessa bacia. Por isso, a vazão específica de cheia dessa bacia é menor que a do Donato, contrariando a tendência de aumento dessa vazão com a área. Porém, se fosse possível computar todo o escoamento sub-superficial dessa bacia junto com o escoamento superficial originado nessa bacia obteria uma vazão específica maior. Isto significaria que nessa escala de vertente $\left(0,125 \mathrm{~km}^{2}\right)$ o escoamento superficial e a infiltração são os processos hidrológicos mais dominantes, de forma que, nesta escala, praticamente não existiria escoamento de base no exutório;

- O plantio direto provocou uma redução nos picos de cheia das bacias menores (Donato e Anfiteatro) e um aumento na bacia do Turcato, provavelmente devido ao escoamento sub-superficial nas vertentes que gera escoamento nos canais para as bacias maiores, além de manter o lençol freático mais alto;

- No período de plantio direto, foi observada uma resposta hidrológica (escoamento superficial) mais uniforme do que no período de plantio convencional, o que corrobora o comentário anterior, já que o escoamento subsuperficial tende a amortecer a resposta da bacia. O período de plantio direto mostrou ser mais regular, com menor variabilidade das condições iniciais em relação ao período convencional, devido a uma maior uniformidade da cobertura vegetal e umidade do solo no plantio direto em relação ao convencional. A umidade do solo se mantém mais constante no plantio direto em relação ao convencional porque o plantio direto favorece a infiltração e diminui a 
evaporação da água retida no solo, por manter uma cobertura vegetal constante.

- Comparando os volumes escoados pelas bacias nos dois períodos de uso do solo, verificamos as seguintes constatações:

o Anfiteatro produz mais escoamento superficial no plantio convencional para precipitações até 30 $\mathrm{mm}$;

o Donato produz mais escoamento superficial no plantio convencional para precipitações até $60 \mathrm{~mm}$; o Turcato gera mais escoamento superficial no plantio direto.

Isso nos leva a concluir que o plantio direto aumenta a capacidade de infiltração do solo, o que produz, nas bacias menores, menos escoamento superficial para precipitações de pequena magnitude, e, na maior, aumento do volume escoado devido ao aumento do escoamento sub-superficial na bacia, que, nesta escala $\left(19,5 \mathrm{~km}^{2}\right)$, influi significativamente no escoamento superficial.

- No período de plantio convencional foi observado que:

a bacia do Anfiteatro produz, em relação às demais bacias, mais escoamento superficial para precipitações até $20 \mathrm{~mm}$;

a bacia do Turcato gera, em relação às demais bacias, mais escoamento superficial para precipitações maiores que $30 \mathrm{~mm}$.

Isso se deve ao fato que, nesse tipo de plantio, o escoamento superficial é gerado na escala de vertente $\left(0,125 \mathrm{~km}^{2}\right)$ para precipitações de pequena magnitude (até $20 \mathrm{~mm}$ ) e que, para precipitações maiores, a influência do escoamento sub-superficial aumenta, de modo que a maior bacia (Turcato) passa a fornecer maior volume escoado.

- No período de plantio direto é o Turcato que gera maior volume escoado, mostrando que, para esse tipo de plantio, o escoamento sub-superficial produzido pela maior capacidade de infiltração do solo é capaz de influir significativamente no volume escoado em bacias dessa escala $\left(19,5 \mathrm{~km}^{2}\right)$

- Em bacias muito pequenas, como as do Anfiteatro e do Donato, o efeito do armazenamento é muito pequeno, fazendo com que a bacia maior (Donato) não amorteça o pico mais do que a menor (Anfiteatro). A bacia do Turcato, por ser a maior, apresenta um amortecimento maior dos picos, de forma que, para uma mesma vazão de pico, esta bacia gera um maior escoamento, conseqüentemente, um maior coeficiente de escoamento. Essa diferença é maior, quanto maior for o pico. O efeito de amortecimen- to no período de plantio direto foi maior, de maneira que foi possível distinguir ajustes diferentes paras as bacias do Anfiteatro e do Donato.

- O plantio direto produz respostas hidrológicas (tempo de pico e volume escoado) que aumentam com o aumento da área da bacia, como era de ser esperar. Mas isso nem sempre é observado no plantio convencional devido à heterogeneidade da cobertura do solo nesse tipo de plantio.

\section{AGRADECIMENTOS}

Esta pesquisa foi desenvolvida com recursos do CNPq e do Fundo de Recursos Hídricos através da FINEP Financiadora de Estudos e Pesquisa do MCT pelos programas RECOPE e REHIDRO.

O primeiro autor agradece o apoio do CNPq pela concessão de bolsa de estudo de mestrado e ao Instituto de Pesquisas Hidráulicas pela infra-estrutura disponibilizada.

\section{REFERÊNCIAS}

BelTRAME, L. F. de S. (coord.), 2000. Consistência de Dados Hidrológicos da Bacia Hidrográfica do Alto Uruguai, SubBacia 75. Porto Alegre, Instituto de Pesquisas Hidráulicas da UFRGS.

BENJAMIN, J. R.; CORNELL, C. A., 1970. Probability, statistics, and decision for Civil Engineers. New York: McGraw-Hill. p. 415-436.

BORGES, A. L. O. e BORDAS, M. P., 1990. Escolha de bacias representativas e experimentais para o estudo da erosão no planalto basáltico sulamericano. In: CONGRESSO BRASILEIRO E ENCONTRO NACIONAL DE PESQUISA SOBRE CONSERVAÇÃO DO SOLO, 8., 1990, Londrina. Anais.

CASTRO, N. M. R., 1996. Ruissellement et érosion sur des bassins versants de grande culture du plateau basaltique du sud du Brésil (Rio Grande do Sul). 224p. Tese (doutorado) - Université Louis Pasteur, Strasbourg.

CASTRO, N. M. R.; CHEVALLIER, P.; GOLDENFUM, J. A., 2000. Projeto Potiribu, atualização 1989 - 1998: dados básicos de fluviometria e pluviometria. Porto Alegre: Instituto de Pesquisas Hidráulicas da UFRGS. (Recursos Hídricos. Publicação n. 35)

CHEVAllier, P., 1993. Projeto Potiribu: dados básicos de fluviometria e pluviometria 1989-1992. Porto Alegre: Instituto de Pesquisas Hidráulicas da UFRGS. (Recursos Hídricos. Publicação n. 26)

CHEVALLIER P., CASTRO N. M. R., 1991. As precipitações na região de Cruz Alta e Ijui (RS-Brasil). In. Simpósio Brasileiro de Recursos Hidricos, 10., 1991 , Rio de Janeiro, Anais 3, pp. 183-192, Rio de Janeiro: ABRH/APRH. 
DOOGE, J. C. I., 1997. Scale problems in Hydrology. In: BURAS, N. (ed.) Reflections on hydrology: science and practice. Washington: American Geophysical Union. p. 89-143

NERC - Natural Environment Research Council, 1975. Flood studies report. London. p. 185-213.

GEOLOGIA DO BRASIL, 1984. Texto explicativo do mapa geológico do Brasil e da área oceânica adjacente incluindo depósitos minerais. Escala 1:2.500.000. Coord. SCHOBBENHAUS, C.; CAMPOS, D. A.; DERZE, G. R.; ASMUS, H. E. Brasília, Departamento Nacional da produção mineral, $500 \mathrm{p}$.

IBGE, 1986. Levantamento de recursos naturais, 33. Folhas SH 22, Porto Alegre e parte das folhas: SH 21 Uruguaiana e SI 22 Lagoa Mirim. Projeto Radam Brasil, 792 p.

INSTITUTO DE PESQUISAS AGRONÔMICAS (IPAGRO), 1989. Atlas Agroclimático do Estado do Rio Grande do Sul. Porto Alegre, v. 3.

KLEMES, V., 1983. Conceptualization and scale in hydrology. Journal of Hydrology, Amsterdam, v. 65, n. 1/3, p. 1-23, Aug.

LEINZ V. 1949. Contribuiçao à geologia dos derrames basálticos do sul do Brasil. Fac. Fil. Ciências e Letras da USP, Bol. CIII, Geologia 5, pp 1-61.

MENDIONDO, E. M.; CASTRO N. M. R.; AUZET, A. V.; CHEVALLIER, P., 1998. Surface flow pathway in subtropical agricultural headwater: a case study from southern Brazil. In: HAIGH, M. J.; KRECEK, J.; RAJWAR, G. S.; KILMARTIN, M. (Editors) - Headwaters: water resources and soil conservation. IAHC / WASWC.

RODRIGUEZ-ITURBE, I. 2000. Ecoyhydrology: A hydrologic perspective of climate-soil-vegetation dynamics. Water Reesources Research Vol 36 N.1 pages 3-9.

SILVA JÚNIOR, O. B., 2001. Ánalise da escala das variáveis bidrlógicas e do uso do solo na bacia do Potiribu - RS. Dissertação (Mestrado) Programa de Pós-Graduação em Recursos Hídricos e Saneamento Ambiental, Instituto de Pesquisas Hidráulicas da Universidade Federal do Rio Grande do Sul.

TUCCI, C. E. M., 1993. Escoamento Superficial. In: TUCCI, C.E.M. (org.) Hidrologia: ciência e aplicação. Porto Alegre: Ed. da Universidade: ABRH: EDUSP. cap. 11, p. 391-441.

TUCCI, C. E. M. e CLARKE, R., 1997. Impacto das mudanças da cobertura vegetal no escoamento: revisão. RBRH Revista Brasileira de Recursos Hídricos, Porto Alegre, v. 2, n. 1, p. 135-152, jan/jun.
The effects of land use change on flow events at the micro and meso scales: Potiribu basin (RS/Brazil)

\section{ABSTRACT}

Changes in the basin landscape have strong impacts on runoff. Land use directly influences hydrologic processes such as runoff, infiltration capacity and landscape interception.

The effects of changes in the tillage system on flow events in the Potiribu basin, in the platean region of Southern Brazil, were analyzed using data from 1989 to 1999 in embedded basins on different scales $\left(0.125 \mathrm{~km}^{2}, 1.10 \mathrm{~km}^{2}\right.$ and $\left.19.50 \mathrm{~km}^{2}\right)$. In these catchments, conventional tillage was substituted for the no-tillage practice in 1994. This paper analyzes precipitation, peak flood events and runoff for both tillage systems.

The headwaters $\left(0.125 \mathrm{~km}^{2}\right.$ catchment) have little discharge regulation and behave differently from the others. It was observed in the data measured that the no-tillage practice reduced peak flood in smaller catchments $\left(0.125 \mathrm{~km}^{2}\right.$ and $\left.1.1 \mathrm{~km}^{2}\right)$ and increased it in the larger basin $\left(19.5 \mathrm{~km}^{2}\right)$. In the no-tillage practice a more uniform bydrological (surface runoff) response was observed than in conventional tillage. In events observed in conventional tillage the beadwaters $\left(0.125 \mathrm{~km}^{2}\right)$ produce specific flows greater than those in the other catchments, but in events observed in no-tillage it is the intermediate catchment $\left(1.1 \mathrm{~km}^{2}\right)$ that produces the highest specific flow.

Key-words: no-tillage practice; bydrological scale; bydrologic variable. 